\section{Surgical management of valve disease}

\section{in the early 21 st century}

Amir M Sheikh, specialist registrar in cardiothoracic surgery; Steven A Livesey, consultant cardiac surgeon

Department of Cardiothoracic Surgery, Southampton General Hospital, Southampton

Valve surgery now comprises $30 \%$ of total cardiac surgical practice in the UK. ${ }^{1}$ Between 2003 and 2008 there were about 30,000 aortic valve operations and 20,000 on the mitral valve. This article reviews acquired adult valvular heart disease, the indications for surgery, the surgical options available and the complications of surgery.

\section{Indications for surgery}

Valves are subject to two haemodynamic

- stenosis, where inadequate opening of the valve presents obstruction to blood flow

- regurgitation, where the valve fails to prevent backflow of blood.

Surgery is undertaken for symptomatic and/or prognostic reasons. Guidelines for management of valvular heart disease (including indications for surgery) were produced by a joint committee of the American Heart Association and the American College of Cardiology in 1998, with subsequent revision in $2006 .^{2}$ Similar, but easier to read, guidelines have been prepared more recently by the European Society of Cardiology. ${ }^{3}$ The indications for surgery for chronic valvular disease are summarised in Table 1. In essence, surgery is indicated when:

The valvular pathology is severe (usually graded on the basis of echocardiographic criteria)

and

Patients have:

symptoms or pathologies: evidence of ventricular dysfunction and/or dilatation

(mainly on echocardiography)

Where symptoms are equivocal, exercise testing can be used for clarification or to assess the haemodynamic response. Valve surgery may be undertaken when the valve lesion is of moderate severity, but cardiac surgery is also indicated for other reasons (eg coronary artery bypass grafting or surgery for ascending aortic aneurysm).

Chronic lesions allow the heart to compensate, but acute severe aortic or mitral regurgitation (eg secondary to acute infective endocarditis (IE) or following myocardial infarction with papillary muscle rupture) causes sudden volume overload which is very poorly tolerated, with inadequate cardiac output and acute pulmonary congestion. Patients develop pulmonary oedema and cardiogenic shock, often requiring inotropic support as well as intubation and ventilation. Emergency surgery is often required.

\section{Options for surgery}

\section{Repair versus replacement}

Valve replacement formed the basis of surgical treatment for diseased valves in the early stages of cardiac surgery and remains the cornerstone. However, there is no perfect valve prosthesis. The feasibility and excellent results of mitral valve repair were demonstrated by Alain Carpentier in his seminal paper 'The French Correction' in $1983 .{ }^{4}$ Subsequent work has confirmed the superiority of repair over replacement for the mitral valve. Patients undergoing repair have better postoperative left ventricular (LV) function, better survival, less morbidity and improved functional status. ${ }^{5-7} \mathrm{~A}$ properly functioning valve requires adequate leaflet tissue with good mobility and an adequate surface area of coaptation. Regurgitant valves are most suitable for repair, especially those affected by leaflet prolapse (secondary to chordal elongation or rupture) or annular dilatation: the leaflets remain pliable and normal leaflet motion and coaptation can be restored using a host of repair techniques. The prolapsing segment can be resected and the leaflet edges re-apposed.

Annular dilatation can be corrected by annuloplasty, usually by securing a prosthetic ring to the mitral annulus. The ring thereby supports the repair by removing tension from the repair suture line, restores normal annular dimensions and prevents future annular dilatation. Endothelial coverage is usually complete after three months and long-term anticoagulation, in the absence of other indications, is not required. Rheumatic valves (including

\section{Key Points}

Valve surgery is indicated for chronic valve lesions when severe and accompanied by symptoms and/or evidence of ventricular dysfunction/dilatation

Development of acute severe valve lesions are poorly tolerated; such patients need resuscitation and assessment for emergency surgery

Mitral valve repair, if feasible, provides better outcomes than replacement. Aortic valve repair is an emerging area that may hold similar promise

Where replacement is necessary, the choice of valve prosthesis rests on an informed decision of the patient after discussion with the surgeon

Surgery for valve disease offers good results. Increasingly older patients, and higher risk patients are undergoing surgery.

KEY WORDS: aortic, cardiac surgery, mitral, tricuspid, valves 
the stenosed mitral valve) are usually unsuitable for repair.

Mitral valve replacement. When mitral valve replacement is necessary, preservation of the subvalvular apparatus is important and offers improved LV function and postoperative survival. ${ }^{8}$ Tension in the chordae and papillary muscles serves not only to prevent prolapse of the mitral leaflets but also as a counter-traction to the LV free wall. This mitral annulopapillary muscle continuity is preserved by not resecting the posterior leaflet, but instead plicating it into the annular sutures necessary for valve replacement. This helps preserve the ellipsoidal shape of the heart and facilitates normal ventricular function.

Aortic valve repair. In situations where the aortic valve cusps remain pliable and mobile, and aortic regurgitation is due to root dilatation or prolapse of one or more leaflets, aortic valve repair is pos- sible. Good results are harder to achieve since there is much less tissue to work with and aortic cusps are thinner and more fragile than mitral leaflet tissues. Aortic root aneurysms, conventionally managed by replacing the native valve as well as the aortic root, can be successfully treated by undertaking segmental replacement of the aorta using a polyester tube (eg Dacron ${ }^{\mathrm{TM}}$ ) but preserving the patient's native aortic valve (so-called valve-sparing aortic root replacement). ${ }^{9}$ Although technically more challenging, good long-term results have been reported. In particular, there is excellent freedom from IE, thromboembolism and anticoagulation-related haemorrhage.

\section{Choice of prosthesis}

There is an extensive variety of prosthetic valves (Fig 1). The two most commonly used are the mechanical valve and the stented tissue valve.

Table 1. Indications for surgery for chronic severe valve lesions (based upon current US recommendations). ${ }^{2}$

\begin{tabular}{|c|c|}
\hline Valve pathology & Indications for surgery \\
\hline \multirow[t]{2}{*}{ Aortic stenosis } & - Symptoms \\
\hline & - LVEF $<50 \%$ \\
\hline \multirow[t]{3}{*}{ Aortic regurgitation } & - Symptoms \\
\hline & - LVEF $<50 \%$ \\
\hline & - LVESD >50 mm or LVEDD >70 mm \\
\hline \multirow[t]{3}{*}{ Mitral stenosis } & - Symptoms (moderate or severe: NYHA III-IV) \\
\hline & - Pulmonary artery hypertension (PA systolic >60 $\mathrm{mmHg}$ ) \\
\hline & - Recurrent emboli despite adequate anticoagulation \\
\hline \multirow[t]{6}{*}{ Mitral regurgitation* } & - Symptoms \\
\hline & - LVEF $\leq 60 \%$ \\
\hline & - $\mathrm{LV}$ ESD $\geq 40 \mathrm{~mm}$ \\
\hline & - New onset AF \\
\hline & - Pulmonary hypertension \\
\hline & $\begin{array}{l}\text { - Asymptomatic, no LV compromise, but }>90 \% \text { likelihood of } \\
\text { achieving repair** }\end{array}$ \\
\hline \multirow[t]{3}{*}{ Tricuspid regurgitation } & - Symptoms \\
\hline & - As concomitant procedure if severe TR and surgery for MV disease \\
\hline & $\begin{array}{l}\text { - As concomitant procedure for less than severe TR and surgery } \\
\text { for MV disease, but pulmonary hypertension or tricuspid annular } \\
\text { dilatation }\end{array}$ \\
\hline
\end{tabular}

* Mitral regurgitation refers to non-ischaemic MR.

** For poor LV $(E F<30 \%$ and/or LVESD $>55 \mathrm{~mm})$ surgery indicated only if repair or mitral valve replacement with chordal preservation likely.

$\mathrm{AF}=$ atrial fibrillation; $\mathrm{EDD}=$ end-diastolic dimension; $\mathrm{EF}=$ ejection fraction; $\mathrm{ESD}=$ end-systolic dimension; $L V=$ left ventricle; $M R=$ mitral regurgitation; $M V=$ mitral valve; $N Y H A=$ New York Heart Association; PA = pulmonary artery; TR = tricuspid regurgitation.

\section{Mechanical valves}

The original mechanical prosthesis was the ball-and-cage (Starr-Edwards) valve, in which a silastic ball was housed in a metal cage. This was followed by secondgeneration tilting disc valves (eg BjörkShiley) where a single disc opens and closes on a hinged strut. The current generation comprises bileaflet valves with which two semicircular discs made of pyrolytic carbon pivot on separate hinges.

Mechanical valves require strict anticoagulation to prevent thrombus formation on the prosthesis which would result in severe valve dysfunction or thromboembolic complications such as stroke. They also have an audible opening and closing click to which most patients (and their partners!) acclimatise. A patient with a mechanical valve presenting in acute respiratory distress and/or shock must be assessed for valve thrombosis with echocardiography, especially if anticoagulant management has been suboptimal. The clicking prosthetic heart sounds will be muffled or absent. The principal advantage of mechanical valves is their durability - the prosthesis usually lasts as long as the patient.

\section{Stented tissue valves}

The stented tissue prosthesis is a trileaflet semilunar valve in which the cusps are made from animal tissues (either bovine pericardium or pig aortic valve) resuspended from a wire stent. The valve undergoes processing to reduce the rate of tissue calcification and degeneration, with improved longevity. Tissue valves do not require anticoagulation and do not click. Their drawback is inevitable degeneration with time, largely due to calcification of the cusps which can lead to valve failure. Current data suggest that actuarial freedom from re-operation due to structural valve deterioration at 15 years is ca $75 \%$ in the aortic position and $65 \%$ in the mitral position. ${ }^{10,11}$

\section{Age- and health-related choice}

The traditional mantra of mechanical valves for younger patients ( $<70$ years) and bioprostheses for older ones no 

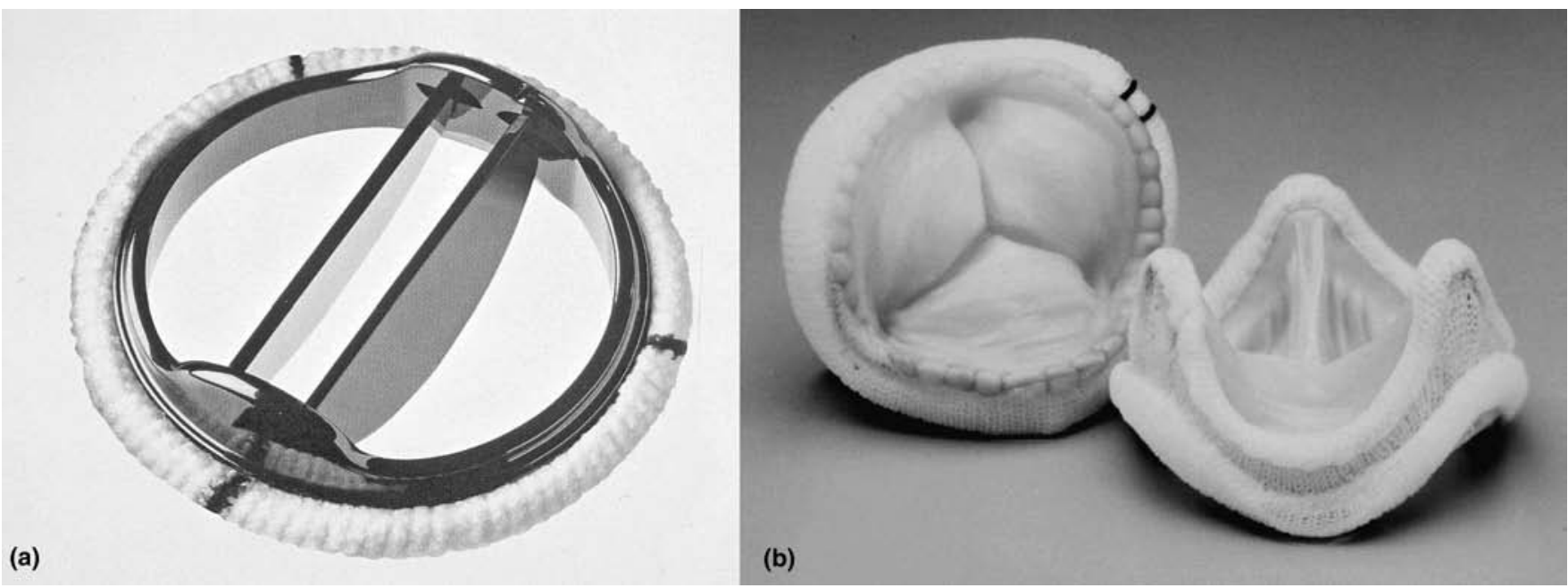

Fig 1. Examples of mechanical and tissue prostheses: (a) bileaflet mechanical valve; (b) stented porcine tissue valve.

longer holds. The choice for a particular patient rests on an informed decision by the patient after discussion with the surgeon. The balance of long-term risks has to be evaluated between future re-operation for a bioprosthesis against the risks of anticoagulation for a mechanical valve. Occasionally, medical considerations may favour one over the other. For example, a bioprosthesis in a young patient in need of multiple other operations will avoid problems of anticoagulation and risk of bleeding. Similarly, a young woman wanting to have children will avoid the teratogenic effects of warfarin.

Mostly, however, lifestyle and patient preference dictate valve choice. Young patients especially keen on avoiding warfarin are increasingly opting for tissue valves, accepting the likely need for a repeat operation in the future. Conversely, some older patients already on warfarin (eg for atrial fibrillation) are happy to continue with warfarin and choose a mechanical valve, thus ensuring no prospect of a repeat operation with a failing tissue valve when they are in their 80 s or 90 s.

\section{Complications and results of surgery}

The complications of valve surgery, divided into early and late, are summarised in Table 2. Death and stroke are the major perioperative complications.
Stroke is nearly always a result of embolic infarction; it can arise as a result of the release of calcium and atheromatous debris following either intraoperative handling of the aorta or excision of the heavily calcified diseased valve. Postoperative atrial fibrillation is common (in approximately 30\%) and is managed with electrolyte correction and anti-arrhythmic medication (amiodarone, beta-blockers or digoxin). It virtually always reverts to sinus rhythm by six weeks.

Fit patients with few comorbidities undergoing straightforward valve surgery

Table 2. Complications of valve surgery.

\begin{tabular}{|c|c|}
\hline $\begin{array}{l}\text { Early } \\
\text { (postoperative) }\end{array}$ & Late \\
\hline Death & $\begin{array}{l}\text { Structural valve } \\
\text { deterioration (bioprosthesis) }\end{array}$ \\
\hline Stroke & Thromboembolism (including stroke) \\
\hline Myocardial & Anticoagulation-related infarction haemorrhage \\
\hline $\begin{array}{l}\text { Haemorrhage with need for } \\
\text { re-exploration }\end{array}$ & IE \\
\hline Infection: & Paravalvular leak \\
\hline $\begin{array}{l}\text { urinary tract, } \\
\text { pneumonia } \\
\text { (common) }\end{array}$ & Valve repair failure \\
\hline - sternal wound $(<5 \%)$ & \\
\hline - early IE (rare) & \\
\hline $\begin{array}{l}\text { Heart block requiring permanent } \\
\text { pacemaker insertion ( } 5 \% \text { of } A V R \text { ) }\end{array}$ & \\
\hline Atrial fibrillation (common) & \\
\hline Peripheral oedema (managed by diuretics) & \\
\hline
\end{tabular}

$\mathrm{AVR}=$ aortic valve replacement; IE = infective endocarditis. 
surgical results, it allows a degree of risk quantification which can form part of the process of informed consent. There are several systems of risk calculation, of which the EuroSCORE is best recognised and most widely utilised. ${ }^{12}$

IE occurs in less than $1 \%$ of replacements per year. The incidence of late endocarditis is markedly less in repaired valves. Thromboembolic complications and anticoagulation-related haemorrhage are significant problems with mechanical prostheses, whilst structural valve deterioration is the major issue with bioprostheses. ${ }^{13}$

The rate of failure and need for reoperation following valve repair is $5-10 \%$ at 10 years for mitral procedures $^{14}$ and similar for valve-sparing aortic root replacement. ${ }^{9}$ This rate is similar to that for re-operation for prosthetic valves. Overall long-term survival (at 20 years) is about $30 \%$ for aortic valve replacement, about $20 \%$ for mitral valve replacement and 50\% for mitral valve repair, ${ }^{15,16}$ but this is clearly also a function of age at the time of original surgery. Importantly, mitral valve repair restores expected survival to that of the age-matched normal population; this is not the case with mitral valve replacement. ${ }^{15,17}$

\section{Redo surgery}

Patients undergoing repeat surgery are increasingly common as a result of increased surgical expertise, patient longevity and improved follow-up. Redo surgery is often technically challenging and carries slightly increased risk on account of scar tissue and adhesions within the mediastinum.

\section{Emerging technologies}

The two latest developments in valve surgery are minimal access and percutaneous techniques.

\section{Minimal access techniques}

Minimal access methods (eg Heartport $^{\mathrm{TM}}$ ) avoid sternotomy and approach the mitral valve through a right mini-thoracotomy with cardiopulmonary bypass achieved by means of groin cannulation. Potential advantages are elimination of sternal complications (infection and breakdown), reduced pain and speedier recovery. ${ }^{18}$

\section{Percutaneous techniques}

Percutaneous approaches have also been developed for aortic valve replacement (transcatheter aortic valve implantation (TAVI)) and mitral valve repair (see accompanying article by MacCarthy). TAVI is currently employed in very highrisk patients with severe aortic stenosis who are unsuitable for conventional surgery. ${ }^{19}$ Catheter-based methods are also emerging for the mitral valve, such as the Mitraclip ${ }^{\mathrm{TM}}$, which clips the anterior and posterior leaflet edges together at the point of greatest leaflet prolapse, thereby attempting to emulate the 'Alfieri edge-to-edge' surgical technique. These methods remain in experimental stages. Patient volumes are still relatively low and long-term results awaited. Standard surgical repair or replacement remains the gold standard.

\section{Summary}

Surgery offers good results for patients with significant valvular heart disease. Valve replacement and repair are the main surgical options. Older patients and redo procedures are increasingly frequent.

\section{References}

1 The Sixth National Adult Cardiac Database Report 2008 (Blue Book), 6th edn. Society for Cardiothoracic Surgery in Great Britain and Ireland, 2009.

2 Bonow RO, Carabello BA, Kanu C et al. ACC/AHA 2006 guidelines for the management of patients with valvular heart disease: a report of the American College of Cardiology/American Heart Association Task Force on Practice Guidelines (writing committee to revise the 1998 Guidelines for the Management of Patients With Valvular Heart Disease): developed in collaboration with the Society of Cardiovascular Anesthesiologists: endorsed by the Society for Cardiovascular Angiography and Interventions and the
Society of Thoracic Surgeons. Circulation 2006;114:e84-231.

3 Vahanian A, Baumgartner H, Bax J et al; Task Force on the Management of Valvular Heart Disease of the European Society of Cardiology; ESC Committee for Practice Guidelines. Guidelines on the management of valvular heart disease: The Task Force on the Management of Valvular Heart Disease of the European Society of Cardiology. Eur Heart J 2007;28:230-68.

4 Carpentier A. Cardiac valve surgery the 'French correction'. J Thorac Cardiovasc Surg 1983;86:323-37.

5 David TE, Uden DE, Strauss HD. The importance of the mitral apparatus in left ventricular function after correction of mitral regurgitation. Circulation 1983;68 (3 Pt 2):II76-82.

6 Perier P, Deloche A, Chauvaud S et al. Comparative evaluation of mitral valve repair and replacement with Starr, Björk, and porcine valve prostheses. Circulation 1984;70(3 Pt 2):I187-92.

7 Zhao L, Kolm P, Borger MA et al. Comparison of recovery after mitral valve repair and replacement. $J$ Thorac Cardiovasc Surg 2007;133:1257-63.

8 David TE, Burns RJ, Bacchus CM, Druck MN. Mitral valve replacement for mitral regurgitation with and without preservation of chordae tendineae. J Thorac Cardiovasc Surg 1984;88(5 Pt 1):718-25.

9 David TE, Feindel CM, Webb GD et al. Long-term results of aortic valve-sparing operations for aortic root aneurysm. J Thorac Cardiovasc Surg 2006;132: 347-54.

10 Banbury MK, Cosgrove DM 3rd, White JA et al. Age and valve size effect on the longterm durability of the Carpentier-Edwards aortic pericardial bioprosthesis. Ann Thorac Surg 2001;72:753-7.

11 David TE, Ivanov J, Armstrong S, Feindel CM, Cohen G. Late results of heart valve replacement with the Hancock II bioprosthesis. J Thorac Cardiovasc Surg 2001;121:268-77.

12 Nashef SA, Roques F, Michel P et al. European system for cardiac operative risk evaluation (EuroSCORE). Eur J Cardiothorac Surg 1999;16:9-13.

13 El Oakley R, Kleine P, Bach DS. Choice of prosthetic heart valve in today's practice. Circulation 2008;117:253-6.

14 Mohty D, Orszulak TA, Schaff HV et al. Very long-term survival and durability of mitral valve repair for mitral valve prolapse. Circulation 2001;104(12 Suppl 1):I1-7.

15 Braunberger E, Deloche A, Berrebi A et al. Very long-term results (more than 20 years) of valve repair with carpentier's techniques in nonrheumatic mitral valve insufficiency. Circulation 2001;104(12 Suppl 1):I8-11. 
16 Oxenham H, Bloomfield P, Wheatley DJ et al. Twenty year comparison of a BjörkShiley mechanical heart valve with porcine bioprostheses. Heart 2003;89:715-21.

17 Enriquez-Sarano M, Akins CW, Vahanian A. Mitral regurgitation. Lancet 2009;373:1382-94.

18 Casselman FP, Van Slycke S, Wellens F et al. Mitral valve surgery can now routinely be performed endoscopically. Circulation 2003;108(Suppl 1):II48-54.

19 Thielmann M, Wendt D, Eggebrecht $\mathrm{H}$ et al. Transcatheter aortic valve implantation in patients with very high risk for conventional aortic valve replacement. Ann Thorac Surg 2009;88:1468-74.

Address for correspondence: Mr S Livesey, Department of Cardiothoracic Surgery, Southampton General Hospital, Southampton SO16 6YD. Email: Steve.Livesey@suht.swest. nhs.uk

\section{Treatment of acquired valvular heart}

\section{disease: percutaneous alternatives}

\section{Rafal Dworakowski, TAVI fellow, King's College Hospital, London; Bernard Prendergast, consultant cardiologist, The John Radcliffe Hospital,Oxford; Olaf Wendler, consultant cardiothoracic surgeon, King's College Hospital, London; Philip MacCarthy, consultant cardiologist, Department of Cardiology, King's College Hospital, London}

The changing epidemiology of valvular heart disease (VHD) has transformed the clinical profile of patients with this disease. ${ }^{1}$ It was previously common to see middle-aged females with rheumatic mitral stenosis (MS), but is now more common to see octogenarians with calcific aortic stenosis (AS). This change in patient characteristics has brought challenges for cardiologists and cardiac surgeons alike, mainly because older patients have complex comorbidity. Such patients are often high risk for surgical valve replacement or repair, still widely regarded as the 'gold standard therapy' for anatomical correction and treatment of most valve defects. This results in under-treatment of these patients, who are often not even exposed to rigorous assessment by the appropriate specialist teams. ${ }^{1}$ It is the combination of an unmet need with a desire to find lower risk, perhaps less invasive approaches that has driven the development of percutaneous valve therapy, now an extremely fastgrowing area of cardiology. Percutaneous and minimally invasive treatment of VHD presents a very attractive option for this high-risk group.

This article focuses on the percutaneous alternatives to open valve surgery and reviews the techniques which currently offer less invasive alternatives. An attempt is also made to give a perspective on the future direction of this fast-moving field.

\section{The aortic valve}

AS is the most common form of VHD, predominantly affecting the elderly. It is usually caused by a degenerative, agerelated process of valve calcification/ destruction. ${ }^{1}$ In our ageing population, AS is an increasingly prevalent condition and well-known to have a poor prognosis with significant morbidity, multiple/prolonged hospital admissions and a marked reduction in quality of life. Once AS becomes symptomatic, life expectancy decreases dramatically.

\section{Balloon aortic valvuloplasty}

The technique of balloon aortic valvuloplasty (BAV) was introduced by Alan Cribier in $1986^{2}$ and is better established as a conventional treatment for congenital AS in children and adolescents. ${ }^{3}$ The morphology of AS in the acquired form of the disease (in elderly patients) is quite different. The degenerate, calcified stenotic valve is much less predictable when dilated with a balloon and the results therefore more variable. Despite this, the immediate results of BAV in calcific degenerative AS are surprisingly good in terms of symptom relief. In the 1990s, data from large BAV registries showed that, even with the original techniques, BAV is a successful method of increasing aortic valve area and reducing the mean and peak aortic valve gradient. ${ }^{4}$ Significant improvements in haemodynamics were observed, including an increase in cardiac output and decrease in left ventricular (LV) end-diastolic pressure. Symptomatic benefits were observed at 30 days with $70 \%$ of survivors having improvement of at least one functional (NYHA) class. However, restenosis of the valve was frequent, occurring in about $50 \%$ of patients within the first few months. As a result, initial enthusiasm for the technique tapered off, particularly when it became apparent that there was no mortality benefit. ${ }^{5}$ Moreover, the procedure itself was considered high risk and cumbersome, and therefore declined in popularity in the early 1990s. 